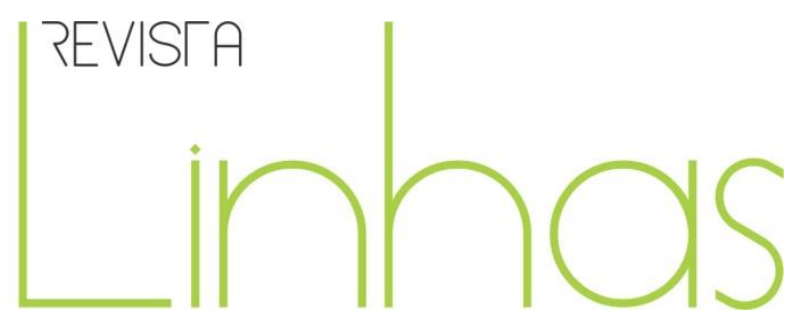

\title{
Do assistencialismo à Base Nacional Comum Curricular (BNCC): movimentos legais e políticos na Educação Infantil
}

\begin{abstract}
Resumo
Este artigo trata da trajetória histórica e política da educação infantil no Brasil. Resultou de uma pesquisa bibliográfica que objetivou discutir, à luz das políticas educacionais, alguns pontos emblemáticos que $o$ atendimento voltado às crianças pequenas foi assumindo desde sua emergência até o momento atual. A relação crechepobreza naturalizou-se ao longo de nossa história e foi a custo de muitas manifestações populares que a educação das crianças de zero a cinco anos entrou na agenda pública. A partir do reconhecimento constitucional da educação infantil como um Direito da Criança (1988) e como parte integrante da educação básica (1996), buscou-se ampliar o atendimento e, ao mesmo tempo, amenizar as desigualdades na oferta de atendimento pelos sistemas de ensino nas diferentes regiões brasileiras. Embora se reconheça avanços no que tange aos compromissos que vêm sendo gradativamente assumidos pelo Estado brasileiro, precisamos reconhecer que temos muitas deficiências quantitativas e qualitativas nesse atendimento. Nesse momento, quando a sociedade brasileira vem discutindo a implementação da Base Nacional Comum Curricular, cabe problematizar em que medida esse documento poderá contribuir para garantir os direitos de aprendizagem a todas as crianças. Conclui-se que, por si só, a BNCC é insuficiente para que mudanças significativas se concretizem. Os direitos de aprender e de se desenvolver requerem, para além de uma base comum, políticas educacionais que priorizem políticas públicas e concretizem investimentos em espaços, aquisição de materiais e formação de professores para a educação infantil.
\end{abstract}

Palavras-chave: Educação de Crianças. Brasil. Legislação.

\section{Circe Mara Marques}

Universidade Alto Vale do Rio do

Peixe - UNIARP - Caçador/SC Brasil

circemaramarques@gmail.com

Ludimar Pegoraro

Universidade Alto Vale do Rio do Peixe - UNIARP - Caçador/SC Brasil

pegoraro1963@hotmail.com

Ezequiel Theodoro da Silva Universidade Alto Vale do Rio do Peixe - UNIARP - Caçador/SC Brasil

emarthi@outlook.com.br

\section{Para citar este artigo:}

MARQUES, Circe Mara; PEGORARO, Ludmiar; DA SILVA, Ezequiel Theodoro. Do assistencialismo à Base Nacional Comum Curricular (BNCC): movimentos legais e políticos na Educação Infantil. Revista Linhas. Florianópolis, v. 20, n. 42, p. 255-280, jan./abr. 2019. 


\title{
From assistencialism to the Common National Basis Curriculum (BNCC): legal and political movements in child education
}

\begin{abstract}
This article deals with the historical and political trajectory of early childhood education in Brazil. It resulted from a bibliographical research that aimed to discuss, in the light of educational policies, some emblematic points that the care given to small children was assumed from their emergence until the present moment. The crèche-poverty relationship has become naturalized throughout our history and it has been at the cost of many popular demonstrations that the education of children aged from zero to five years years has entered the public agenda. Based on the constitutional recognition of children's education as a Right of the Child (1988) and as an integral part of basic education (1996), it was sought to increase care and, at the same time, to alleviate the inequalities in the provision of care by education systems in different Brazilian regions. Although we recognize progress in the commitments that have been gradually assumed by the Brazilian state, we must recognize that we have many quantitative and qualitative deficiencies in this service. At this moment, when the Brazilian society has been discussing the implementation of the National Curricular Common Base, it is possible to problematize to what extent this document can contribute to guarantee the rights of learning to all the children. It is concluded that BNCC alone is insufficient for significant changes to take place. The right to learn and develop requires, in addition to a common basis, educational policies that prioritize public policies and concretize investments in spaces, acquisition of materials and training of teachers for early childhood education.
\end{abstract}

Keywords: Education of children. Brazil. Legislation. 


\section{Introdução}

Uma teoria crítica sobre o poder, sobre o Estado e sobre o poder do Estado é um ponto de partida necessário para o estudo da política educativa, pois defende, ao mesmo tempo, a ideia de que "qualquer estudo da educação enquanto política pública deve abordar as questões do contexto organizacional no qual o poder (enquanto expressão de dominação) é exercido" (MORROW; TORRES, 1997, p. 313).

Tomando essa ideia inicial como um pressuposto, nos perguntamos em que medida as práticas educacionais direcionadas às crianças pequenas estiveram vinculadas ao cenário econômico, político e social de cada época de nossa história. Para uma análise mais consistente sobre essa questão no Brasil, realizamos uma pesquisa documental e bibliográfica abrangendo aspectos históricos e políticos da educação das crianças de zero a cinco anos. A pretensão central da análise é a de elencar, à luz das políticas educacionais, alguns pontos emblemáticos que os atendimentos voltados às crianças pequenas assumiram desde a sua emergência até o momento atual. Entendemos que refletir sobre os interesses que orientaram e orientam essa engrenagem política, que funciona desde o surgimento das creches, pode ajudar a compreender e a criticar a naturalização de certas práticas pedagógicas contemporâneas. Para isso, tomamos como referência alguns documentos legais, do passado e do presente, relacionados ao nosso campo de pesquisa e, também, estudos desenvolvidos por pesquisadores no campo das Políticas Públicas para Educação Infantil, entre eles: Paiva (1973), Oliveira (2002a; 2002b;), Marcílio (1999), Bujes (2001), Guimarães (2017), Faria (2000), Kuhlmann (1998), Kramer (1993), Rosenberg (2002), Arce (2001), Campos (2002, 2010), Flores e Albuquerque (2015).

Iniciaremos a discussão fazendo referência à chegada dos primeiros europeus no Brasil e o impacto dessa chegada na educação das crianças. Na sequência, discutiremos, brevemente, alguns pontos que consideramos importantes destacar na intenção de compreender os rumos que a educação infantil vem tomando; dentre eles, o crescimento da população e a emergência da criação de espaços de acolhimento às crianças abandonadas, o surgimento das primeiras regulamentações governamentais e a oferta da educação infantil como um direito da criança. Por fim, elencaremos as implicações dessa retrospectiva na elaboração de uma Base Nacional Comum Curricular (BNCC). 


\section{As primeiras caravelas e seus legados}

Os primeiros europeus que chegaram ao Brasil no século XVI impuseram os padrões da civilização europeia aos povos indígenas, até então únicos habitantes destas terras. Foi o início de uma "conquista” colonialista que até hoje, apesar da proclamação da independência e da constituição da República, nos mantém, de certo modo, submetidos à cultura e aos interesses políticos e socioeconômicos das principais potências estrangeiras.

Aprender uma língua e um código de escrita desconectados de sua cultura e amar um deus que não era o seu Deus foram princípios educativos impostos pelos jesuítas às crianças indígenas. Para tal, os religiosos organizaram classes de alfabetização, sendo que “[...] eram escolhidos os filhos dos caciques para serem educados" (PAIVA, 1973, p. 27), ou melhor, para serem catequizados. Essa ação educativa, direcionada às crianças filhas de líderes tribais, foi uma forma de disseminar a cultura europeia e, também, garantir aos núcleos de colonização portuguesa a proteção contra os ataques indígenas (PAIVA, 1973). Nesse sentido, a instrução infantil, trazida junto nas primeiras caravelas, constituiu um mecanismo político-ideológico que objetivava dominar e escravizar os povos que aqui viviam.

\section{A invisibilidade da educação das crianças pobres por parte do Estado}

Ao trabalho escravo dos povos indígenas, mais tarde foi somado o dos negros. $\mathrm{O}$ crescimento da população e o aumento da miséria levaram a sociedade a buscar uma solução para o atendimento às crianças abandonadas e excluídas.

No século XVII, no Brasil, de acordo com Oliveira (2002a), as crianças órfãs e abandonadas eram informalmente adotadas ou recolhidas em instituições de misericórdia:

No meio rural, onde residia a maior parte da população do país na época, famílias de fazendeiros assumiam o cuidado das inúmeras crianças órfãs ou abandonadas, geralmente frutos da exploração sexual da mulher negra e índia pelo senhor branco. Já na zona urbana, bebês abandonados pelas mães, por vezes filhos ilegítimos de moças pertencentes a famílias 
com prestígio social, eram recolhidos nas "rodas de expostos" existentes em algumas cidades desde o início do século XVIII. (OLIVEIRA, 2002a, 91)

As rodas dos expostos ${ }^{1}$ tiveram origem na Itália, no século XII, e por mais de cem anos foram as únicas instituições de assistência à criança abandonada em todo o Brasil. $O$ seu surgimento dessas instituições deve-se ao grande número de recém-nascidos abandonados em portas de igrejas, em portas de casas de famílias ou largados ao relento, vindo, então, a morrer de fome, de frio ou serem comidos por animais (MARCILIO, 1999). Diante dessa realidade, autoridades baianas, preocupadas com a situação dos bebês abandonados na cidade de Salvador, reivindicaram à Coroa a abertura de uma roda na Bahia. A Santa Casa aceitou essa incumbência, contanto que recebesse auxílio financeiro da Coroa. A partir de então, foram criadas, no Brasil, treze rodas de expostos ao longo dos períodos Colonial, Imperial e início da República.

As Santas Casas eram instituições que, na época, mantinham-se graças a doações daqueles que praticavam caridade com vistas a alcançarem a salvação de suas almas. Assim, na impossibilidade de atender a todas as crianças abandonadas na roda, os pequenos eram encaminhados, pela rodeira, a uma ama-de-leite, ${ }^{2}$ com quem ficavam até completarem três anos. Passado esse período, grande parte das crianças novamente se encontrava sem lar e "acabavam perambulando pelas ruas, prostituindo-se ou vivendo de esmolas ou de pequenos furtos" (MARCILIO, 1999, p. 73).

Como vimos acima, embora assistência à infância abandonada fosse de competência das câmaras municipais durante o período colonial, era a sociedade civil que enfrentava o problema, por meio da adoção informal (MARCILIO, 1999).

A campanha pela abolição das rodas, iniciada na Europa no século XIX, contou, no Brasil, com o apoio de médicos higienistas interessados em reduzir os altos índices de mortalidade infantil que ocorriam nessas instituições, e também com o apoio dos juristas

\footnotetext{
${ }^{1} \mathrm{O}$ nome da roda provém do dispositivo onde se colocavam os bebês que se queria abandonar. Sua forma cilíndrica, dividida ao meio por uma divisória, era fixada no muro ou na janela da instituição. No tabuleiro inferior, em uma abertura externa, o expositor depositava a criancinha que enjeitava. A seguir, ele girava a roda e a criança já estava do outro lado do muro. Puxava-se uma cordinha com uma sineta, para avisar a vigilante ou rodeira que um bebê acabava de ser abandonado e o expositor furtivamente retirava-se do local, sem ser identificado (MARCíLIO, 1999, p. 55).
}

${ }^{2}$ As amas-de-leite eram mulheres extremamente pobres, ignorantes e residentes nas cidades. 
interessados na criação de leis protetoras à criança abandonada com vistas a contornarem os problemas oriundos da adolescência. No Brasil, a eliminação das rodas representou um passo muito curto quando consideramos tanto a melhoria na qualidade de atendimento como a seriedade no compromisso assumido pelas autoridades públicas. Em decorrência do ingresso das mulheres no trabalho assalariado, surge, no início da industrialização, uma nova questão social: Quem assumiria o cuidado dos filhos e filhas das operárias, enquanto as mesmas estivessem no trabalho? Entregar os cuidados de seus filhos às "criadeiras" foi o caminho encontrado pelas mães operárias, no início do século XX. As criadeiras, mulheres pobres que, em troca de dinheiro, cuidavam de crianças sem as adequadas condições materiais e afetivas. Essas mulheres chegaram a ser chamadas de "fazedoras de anjos" (OLIVEIRA, 2002a, p. 95), em função do elevado índice de mortalidade de crianças por elas atendidas. Ações de combate aos altos índices de mortalidade infantil nesse período foram mais uma preocupação com o futuro da mão de obra e a economia do país, do que uma preocupação com a criança propriamente dita.

Foi durante o regime imperial, que esse padrão foi sendo, aos poucos, modificado pela intervenção do poder. Essa intervenção se deu através da constituição de redes de assistência, entre elas os Recolhimentos para Meninas Pobres e os Colégios de Órfãos. Esses estabelecimentos, apesar de submetidos à administração privada, sobretudo das Casas de Misericórdia, recebiam subvenção e regulação públicas (MARCíLIO, 1999).

\section{Assistência das crianças: as primeiras regulamentações governamentais}

Como vimos até aqui, durante muito tempo, não foi possível identificar compromisso governamental com a educação das crianças pequenas (Bujes, 2001). A responsabilidade pelo atendimento ficava relegada à família, ao grupo social do qual faziam parte ou a instituições de caridade, no caso de crianças pobres e abandonadas.

Durante o período Imperial, mais precisamente em 1879, o artigo $2^{\circ}$ do Projeto da Reforma de Leôncio de Carvalho determinou a criação dos Jardins de Infância para crianças de três a sete anos, embora os recursos previstos fossem para crianças dos sete aos quatorze anos. 
Em 1899, o médico Moncorvo Filho liderou a criação do Instituto de Proteção e Assistência à Infância do Brasil (IPAIB), tendo como um dos propósitos, a criação de creches e pré-escolas para crianças menores de oito anos (GUIMARÃES, 2017).

Na década de 1920 e no início da década de 1930, surgem reivindicações operárias, dirigidas às indústrias e ao Estado, por locais de atendimento às crianças durante o período de trabalho das mães. Iniciam-se, então, as primeiras regulamentações do atendimento às crianças pequenas em escolas maternais e jardins-de-infância. Mudanças nessa realidade aconteceram não só em decorrência de novas necessidades políticas e econômicas da sociedade moderna, mas também em função de avanços nos campos da Psicologia e da Sociologia, que contribuíram para o florescimento de novas concepções de infância, de família e de gênero.

A esse respeito, Bujes (2001) destaca que o surgimento das creches e pré-escolas se deu em decorrência de mudanças econômicas, políticas e sociais, entre elas a incorporação das mulheres no trabalho assalariado e às mudanças nas organizações familiares. Soma-se a isso, um conjunto de ideias novas sobre a infância, sobre o papel da criança na sociedade e sobre como torná-la, através da educação, um indivíduo produtivo e ajustado às exigências do conjunto social. Guimarães (2017) afirma que "em algumas cidades do país, as primeiras creches substituíram a Casa dos Expostos, com seu caráter assistencial e de guarda voltado ao atendimento das crianças e famílias empobrecidas" (2017, p. 90).

Em 1924, o interesse pelos ideais da Escola Nova ${ }^{3}$ leva educadores simpatizantes desse movimento a fundarem a Associação Brasileira de Educação. Mais tarde, em 1932, esse movimento ganha consistência com o documento Manifesto dos Pioneiros da Educação Nova. ${ }^{4}$ Os ideais escolanovistas tiveram repercussão na educação infantil;

\footnotetext{
${ }^{3}$ Como princípios básicos da Escola Nova, destacam-se: a valorização dos interesses e necessidades da criança; a defesa da ideia do desenvolvimento natural; a ênfase no caráter lúdico das atividades infantis; a crítica à escola tradicional, porque os objetivos desta estão calcados na aquisição de conteúdos; e a consequente prioridade dada pelos escolanovistas ao processo de aprendizagem (KRAMER, 1993, p. 25).

${ }^{4}$ Documento composto de dez itens com várias subdivisões. $O$ item $n^{\circ} 8$ referia-se especificamente à criação de instituições de educação e assistência física e psíquica à criança em idade pré-escolar (de zero a seis anos), prevendo a organização de jardins de infância. Essa modalidade de ensino era novamente mencionada no item $n^{\circ} 10$, para enfatizar a necessidade de uma organização escolar unificada que se estendesse da pré-escola até a universidade, com vistas à seleção dos melhores, aconselhando o máximo desenvolvimento dos alunos normais em escolas comuns e o cuidado com os anormais e subnormais em escolas especiais (DROUET, 1990, p. 55).
} 
contudo, dirigiram-se mais ao atendimento de crianças socialmente privilegiadas, que frequentavam os jardins de infância, do que aos parques infantis, ${ }^{5}$ onde eram atendidas crianças das classes populares (FARIA, 2000, p. 29).

Na década de 1940, houve uma ampliação de iniciativas governamentais de atendimento; entretanto, as creches ainda "eram planejadas como instituição de saúde" (OLIVEIRA, 2002a, p. 100), ou seja, voltadas aos cuidados relacionados à alimentação, à higiene e à segurança física das crianças. Outras entidades assistenciais, como a Legião Brasileira de Assistência (LBA), Fundo das Nações Unidas para a Infância (UNICEF) e Organização Mundial de Educação Pré-escolar (OMEP), também ganharam importância e contribuíram na mobilização de recursos para o atendimento de crianças pobres em especial.

Cabe destacar a emergência de alguns documentos legais nesse período, entre eles: o Decreto-Lei $n^{\circ}$ 2024, de 17 de fevereiro de 1940, que fixa as bases da organização da proteção à maternidade, à infância e à adolescência em todo o País; o Decreto-Lei $\mathrm{n}^{\circ}$ 5.452, de $1^{\circ}$ de maio de 1943, que dispõe nos artigos 397 e 398 que "As instituições de Previdência Social construirão creches nas vilas operárias de mais de cem casas e nos centros residenciais, de maior densidade, dos respectivos segurados"; o Decreto-Lei $\mathrm{n}^{\circ}$ 229, de 28 de janeiro de 1967, que altera dispositivos da Consolidação das Leis do Trabalho, aprovada pelo Decreto-Lei $n^{\circ} 5.452$, de $1^{\circ}$ de maio de 1943 , estabelecendo que toda empresa onde trabalhem pelo menos 30 (trinta) mulheres com mais de 16 (dezesseis) anos de idade ter de oferecer local apropriado onde as empregadas tenham seus filhos guardados sob vigilância e assistência no período da amamentação. Vimos, então, que ao longo de 50 anos, a partir do governo Vargas, foram se regulamentando os direitos trabalhistas, dentre os quais a possibilidade das mães terem um local para seus filhos durante a fase de amamentação.

Ao discurso assistencialista, por volta dos anos de 1960, foi somada a ideia de que a marginalidade e a criminalidade também poderiam ser contidas a partir do atendimento das crianças carentes nessas instituições. A LDB, Lei 4.024/61, em seu artigo 23,

\footnotetext{
${ }^{5}$ Criados em 1935 por Mário de Andrade, poeta e diretor do Departamento de Cultura (DC) da prefeitura do município de São Paulo na gestão do prefeito Fábio Prado, os Parques Infantis (PIs) vieram a ser a primeira experiência brasileira pública municipal de educação (embora não escolar) para crianças de três a 12 anos, oriundas de famílias operárias (FARIA, 2000, p. 29).
} 
estabelece que "A educação pré-primária se destina aos menores de até sete anos, será ministrada em escolas maternais ou nos jardins-de-infância”. Durante o período dos governos militares, após 1964, persiste a ideia de creches e pré-escolas como instituições assistenciais às crianças carentes não só no campo da saúde, mas também em âmbito cultural. O intenso ingresso das mulheres de classe média no mercado de trabalho, e os posicionamentos favoráveis de médicos e psicólogos destacando a importância dos primeiros anos de vida, suscitaram o crescimento das creches e pré-escolas para atender crianças cada vez menores. A partir dessa nova realidade, estruturam-se propostas pedagógicas compensatórias, visando a suprir carências das crianças de classes populares e a prepará-las para o ingresso no ensino fundamental. Mantinha-se, então, a educação diferenciada para crianças pobres e crianças de classe média, ou seja,

[...] Enquanto discursos compensatórios ou assistencialistas continuavam dominantes no trabalho dos parques que atendiam filhos de operários e nas creches que cuidavam das crianças de famílias de baixa renda, propostas de desenvolvimento afetivo e cognitivo para crianças eram adotadas pelos jardins-de-infância onde eram educadas as crianças de classe média. (OLIVEIRA, 2002a, p. 110)

Drouet (1990, p. 82), analisando as funções que a pré-escola foi assumindo desde o seu surgimento no Brasil, também aponta esse modelo de atendimento diferenciado em função da classe social das crianças atendidas, de modo que:

A educação pré-escolar brasileira teve, historicamente, duas funções diferentes: educação para elite, desenvolvida nos jardins-de-infância, criados para crianças de classe média alta, com função socializadora e recreativa, e as instituições assistenciais benemerentes para órfãos e para crianças abandonadas, com função de abrigo e proteção. Infelizmente, essa função assistencial benemerente e não educacional prevalece até hoje. Assim, quando se pensa em grandes programas de assistência à infância carente, pensa-se logo em guarda, alimentação e recreação dessas crianças e, é claro, em propaganda eleitoral de parlamentares, prefeitos e governadores.

Também Kuhlmann (1998) chama atenção para o quanto as instituições assistenciais contribuíram no processo de educação para a subalternidade. A educação de caráter assistencial buscou, a partir dos anos de 1970, assumir uma função "pedagógica” 
com vistas, especialmente, a compensar a carência cultural de crianças menos favorecidas economicamente. No entanto, essa função pedagógica das creches e préescolas ainda não tinha o reconhecimento constitucional por parte do Estado brasileiro. Embora a Lei $\mathrm{n}^{\circ}$ 5692/71, aprovada durante o Regime Militar, estabelecesse a obrigatoriedade escolar dos sete aos 14 anos, certas escolas públicas matriculavam crianças de seis anos, objetivando reduzir os índices de repetência na primeira série.

Ferrari (1982), analisando a proposta oficial de educação pré-escolar nos anos 70, destaca que o interesse pela educação pré-escolar, na época, não aconteceu em decorrência de um reconhecimento das necessidades específicas dessa fase, mas como uma estratégia para contornar os altos índices de reprovação, evasão e fracasso escolar.

Para combater essa situação, incrementaram-se programas compensatórios com vistas a suprir as carências culturais, alimentares e afetivas das crianças. Esses programas, segundo Ferrari (1982), não alcançaram bons resultados, uma vez que a solução para o problema do fracasso escolar não deve ser buscada na pré-escola, pois a mesma tem valor em si mesma e não pode se restringir à "salvação da escola". Essa problemática exige soluções de ordem estrutural. Kramer (1993), contudo, faz referência ao papel político que a educação compensatória desempenhou nos ano de 1970, considerando que não só impulsionou o debate sobre as funções e os métodos pedagógicos que devem nortear o trabalho na pré-escola, mas também legitimou o modelo educacional da educação pré-escolar, diferenciando-se do modelo assistencialista.

Rosenberg (2002) afirma que, no Brasil, a partir dos anos de 1970, as políticas da educação infantil foram fortemente influenciadas por "modelos ditos 'não formais' e baixo investimento público", provenientes de organizações como Unesco e Unicef. Com informações obtidas nessas organizações, a referida pesquisadora destaca que a proposta de modelo para a educação infantil em países subdesenvolvidos seguia estas orientações:

- a expansão da educação infantil constitui uma via para combater a pobreza (especialmente desnutrição) no mundo subdesenvolvido e para melhorar o desempenho do ensino fundamental, portanto, sua cobertura deve crescer; - os países pobres não dispõem de recursos públicos para expandir, simultaneamente, o ensino fundamental (prioridade número um) e a El; 
- a forma de expandir a El nos países subdesenvolvidos é por meio de modelos que minimizem investimentos públicos, dada a prioridade de universalização do ensino fundamental; - para reduzir os investimentos públicos, os programas devem se apoiar nos recursos da comunidade, criando programas denominados "não formais", "alternativos", "não institucionais", isto é espaços materiais, equipamentos e recursos humanos disponíveis na comunidade, mesmo quando não tenham sido concebidos ou preparados para essa faixa etária e para seus objetivos. (ROSENBERG, 2002, p. 33)

As intervenções desses órgãos, segundo Rosenberg, incentivam a implantação de políticas de baixo custo e ainda colocam a educação infantil em segundo plano no que se refere a investimentos públicos. A organização de creches domiciliares veio ao encontro de um modelo de atendimento em massa que previa a expansão do atendimento às crianças com o mínimo de investimentos públicos. Com a implementação desse modelo, expandiu-se, entre os anos de 1970 e 1980, o atendimento às crianças; contudo, a falta de qualificação para o magistério das pessoas da comunidade que se dispunham a "cuidálas", a metodologia que desconsiderava a especificidade dos desejos, necessidades e capacidades das crianças nessa fase de desenvolvimento, a falta de infraestrutura básica e de materiais pedagógicos contribuiu para a baixa qualidade desse tipo de atendimento oferecido às crianças. Até então, o atendimento nas creches tinha uma função assistencialista no sentido de oferecer aos filhos das trabalhadoras o suprimento das necessidades básicas, tais como higiene, descanso e alimentação.

Kramer (1993) destaca que as iniciativas populares foram manipuladas por interesses políticos, preocupados em expandir uma pré-escola de baixo custo através do uso do serviço da população, sem conceder-lhe espaço na elaboração das propostas educativas. Essa mesma pesquisadora ainda enfatiza a impossibilidade de se oferecer atendimento de qualidade a partir da implantação de programas de baixo custo e ressalta que os custos da educação infantil são altos e devem ser assumidos pelo Estado.

Segundo Silva (2002, p. 178), "uma visão democrática da qualidade em educação deve concentrar-se não apenas na questão de sua distribuição, mas também no questionamento daquilo que é distribuído". Assim, a quantidade e a qualidade no atendimento de crianças não podem ser dissociadas, pois o brilho da expansão de uma delas pode ocultar a importância e a necessidade da outra. 
O atendimento à infância foi profundamente influenciado pela perspectiva médico-higienista, como parte de um projeto maior de saneamento, necessário a um país que se queria civilizado e moderno. Somente na década de 1940, o Estado desenvolve uma política assistencial de caráter global, equipando as instituições oficiais de atendimento à infância com pessoal “qualificado” na área de saúde. (SANCHEZ, 2003)

A expressão educação pré-escolar, usada até os anos 80, situava e educação infantil fora da educação formal, pois "expressava o entendimento de que a educação infantil era etapa anterior, independente e preparatória para a escolarização, que só teria seu começo no Ensino Fundamental” (BRASIL, 2017, p. 33).

\section{Enfim, a educação das crianças como um direito proclamado!}

O fim do Regime Militar abriu espaço para manifestações e mobilizações sociais requerendo uma nova Constituição Nacional. Formou-se a Comissão Nacional Criança Constituinte com a intenção de mobilizar a opinião pública em favor dos direitos da criança.

O reconhecimento constitucional da educação infantil como um direito da criança e de sua família tornou-se realidade com a promulgação da Constituição de 1988 e teve prosseguimento com o Estatuto da Criança e do Adolescente (ECA/1990), com a Lei de Diretrizes e Bases da Educação Nacional (LDB/1996) e com outras legislações estaduais e municipais que, nos últimos anos, trouxeram importantes inovações ao campo da educação infantil. Estudos, abrangendo políticas e legislações voltadas a crianças, fizeram emergir opiniões e posicionamentos diversos e, em alguns casos, bastante divergentes. Essas opiniões, oriundas do norte, do sul, do leste e do oeste do Brasil, são indicativas de que são crescentes o interesse e a atenção para com o planejamento e aplicação de políticas de educação infantil. Analisando a relação entre a legislação e a política nacional para a educação infantil, Oliveira (2002b, p. 35) destaca que:

[...] os avanços na legislação levantam desafios que, na verdade, não são conquistados da noite para o dia. Um primeiro passo, com certeza, diz respeito a mudanças de concepções, crenças e valores que não se transforma de uma hora para outra. [...] Essas concepções dizem respeito não só à criança, seu desenvolvimento e educação, como 
também ao papel do Estado, da sociedade e dos profissionais que atuam na educação infantil.

A Constituição Federal de 1988, em seu artigo $7^{\circ}$, inciso XXV, assegurou aos trabalhadores e trabalhadoras o direito à "assistência gratuita aos filhos e dependentes desde o nascimento até os seis anos de idade em creches e pré-escolas" (BRASIL, 1988) e, ao mesmo tempo, no art. 208, inciso IV, estabelece que o dever do Estado para com a educação será efetivado mediante a garantia de "atendimento em creche e pré-escola às crianças de zero a seis anos de idade".

O Estatuto da Criança e do Adolescente (ECA), Lei Federal $n^{\circ} 8.069$, publicada em 13 de julho de 1990, apresenta um maior detalhamento de cada um dos direitos da criança e do adolescente, e cria os Conselhos encarregados de traçar diretrizes e de zelar pelo respeito a esses direitos.

Em 20 de dezembro de 1996, foi aprovada a Lei $n^{\circ}$ 9.394, que fixa as atuais Diretrizes e Bases da Educação Nacional (LDB). Essa legislação introduziu uma série de inovações em relação à Educação Básica, dentre elas a integração das creches nos sistemas de ensino, compondo, junto com as pré-escolas, a primeira etapa da Educação Básica. Também foi reafirmado o atendimento gratuito em creches e pré-escolas, garantido na Constituição Federal.

A LDB impulsiona a autonomia das escolas no que tange à flexibilidade na organização do currículo e a pluralidade de métodos pedagógicos, desde que assegurem o desenvolvimento integral da criança até aos seis anos de idade, em seus aspectos físico, psicológico, intelectual e social, complementando a ação da família e da comunidade.

A partir de então foi estipulado um prazo de até dez anos para que as creches passassem a integrar os sistemas de ensino e construíssem seus projetos pedagógicos. A primeira modificação importante na LDB foi introduzida pela Lei 11.274/2006 que estendeu o ensino fundamental de oito para nove anos, com matrícula no primeiro ano (antiga primeira série) aos seis anos de idade. Os municípios, os estados e o Distrito Federal receberam o prazo até 2010 para implementar essa determinação.

Com o objetivo de auxiliar os professores na superação da tradição assistencialista de atendimento às crianças pequenas, instrumentalizando-os para a realização do 
trabalho educativo, em 1998, o MEC distribui às escolas públicas o Referencial Curricular Nacional para a Educação Infantil (RCNEI). Esse material, organizado em três volumes, buscou orientar a reflexão acerca dos objetivos, conteúdos e orientações didáticas para professores de educação infantil, respeitando seus estilos pedagógicos e a diversidade cultural brasileira (BRASIL, 1998).

A organização e distribuição desse documento provocaram críticas por parte de alguns pesquisadores. Bujes (2001, p. 18) afirmou que o RCNEI visa a "moldar e modelar as condutas infantis" e ainda aponta que o mesmo está "conectado com objetivos políticos mais amplos de gestão social”. Segundo a autora, esse material, ao definir organização do tempo, do espaço, das decisões pedagógicas e administrativas, constituiu-se em esforço organizado para a fabricação de certos tipos de sujeitos idealizados a partir dos estudos oriundos do campo da psicologia do desenvolvimento.

Arce (2001, p. 270) refere-se ao RCNEl como um retrocesso para a educação infantil e destaca que o documento representa uma discriminação do professor de educação infantil que, pela pouca qualificação, não necessita nada mais do que "um conjunto de receitas e instruções para a realização de seu trabalho". Em continuidade, a referida autora ainda faz referência ao "cunho psicologizante/cognitivista do atendimento infantil, e que não aproveita a produção existente na área, terminando por não privilegiar as especificidades deste atendimento".

Em 1999, a Resolução CEB $\mathrm{n}^{\circ}$ 1, de 7 de abril de 1999, instituiu as Diretrizes Curriculares Nacionais para a Educação Infantil (DCNEl/1999) a serem observadas na organização das propostas pedagógicas das instituições de educação infantil integrantes dos diversos sistemas de ensino. Na medida em que outras demandas e novos desafios foram colocados para a Educação Infantil, tornou-se necessária a revisão e atualização dessas Diretrizes. Entre os desafios, cita-se "a ampliação das matrículas, a regularização do funcionamento das instituições, a diminuição no número de docentes nãonhabilitados na Educação Infantil e o aumento da pressão pelo atendimento" (PARECER 20/2009). Cabe, ainda, destacar que nesse momento tramitava no Congresso Nacional a proposta de ampliação da obrigatoriedade na Educação Básica, reforçando a necessidade de novos marcos normativos para a Educação Infantil. 
A Resolução CNE/CEB 5/2009 fixou as novas Diretrizes Curriculares Nacionais para a educação infantil. Esse documento, articulado com as Diretrizes Curriculares Nacionais para a Educação Básica, reúne "princípios, fundamentos e procedimentos para orientar as políticas públicas e a elaboração, planejamento, execução e avaliação de propostas pedagógicas e curriculares de educação infantil” (BRASIL, 2010, p. 11).

De acordo como o Parecer MEC/CNE n²0/2009,

As creches e pré-escolas se constituem, portanto, em estabelecimentos educacionais públicos ou privados que educam e cuidam de crianças de zero a cinco anos de idade por meio de profissionais com a formação específica legalmente determinada, a habilitação para o magistério superior ou médio, refutando assim funções de caráter meramente assistencialista, embora mantenha a obrigação de assistir às necessidades básicas de todas as crianças. (BRASIL, 2009a, p. 4)

As DCNEl/2009 compõem um documento que busca se desvencilhar da perspectiva desenvolvimentista da psicologia, assumindo um viés mais sociológico, que concebe a criança como sujeito histórico e de direitos. Define os princípios éticos, políticos e estéticos para serem seguidos pelas escolas na elaboração de suas Propostas Pedagógicas (PP) e pontua as brincadeiras e as interações como eixos sobre os quais devem assentar-se as PP. Revela, explicitamente, a preocupação do Ministério da Educação com as especificidades da ação pedagógica com bebês, a antecipação de conteúdos previstos para o ensino fundamental, a diversidade, a garantia do direito a brincadeiras, a organização dos tempos, espaços e materiais, a avaliação, a transição para o ensino fundamental, entre outras apontadas nesse documento. Diferentemente do RCNEI, não definiu conteúdos e orientações didáticas para a educação infantil. Considerando o pouco detalhamento das DCNEl, muitas foram as dúvidas, as interpretações e as controvérsias por parte dos profissionais da educação infantil sobre o modo como desenhar o currículo de sua escola a partir desse documento orientador.

Ainda em 2009 é aprovada a Ementa Constitucional 59 que estende a educação básica obrigatória e gratuita dos 4 (quatro) aos 17 (dezessete) anos de idade. Essa medida foi considerada bastante polêmica, uma vez que foi aprovada 
sem que se previsse um período de transição, nem regras claras sobre a idade exata em que as crianças deveriam ser aceitas no primeiro ano, nem o treinamento em serviço para que os professores se preparassem para atender aos estudantes mais novos, nem esclarecimentos aos pais sobre os motivos dessa mudança, nem a adaptação de prédios, equipamentos, mobiliários e materiais escolares. (CAMPOS, 2010. p. 10)

Nesse momento, no campo da educação infantil, ainda vivemos os impactos da Lei $\mathrm{n}^{\circ}$ 12.796, de 4 de abril de 2013, que altera a LDB, estabelecendo a obrigatoriedade de matrículas das crianças de quatro anos na Educação Infantil e outras inovações no que se refere ao calendário escolar, frequência, tempo de permanência na escola, avaliação e expedição de documentos. O calendário escolar passou a funcionar com carga horária mínima de 800 horas, 200 dias letivos e com 60\% de frequência obrigatória. As matrículas em regime parcial deverão cumprir, no mínimo, 4 horas e, 7 horas para período integral. As crianças serão avaliadas mediante acompanhamento e registro do desenvolvimento, sem o objetivo de promoção, mesmo para o acesso ao ensino fundamental. Também está legalmente exigida a expedição de documentação que ateste os processos de aprendizagem e desenvolvimento da criança.

A Lei $n^{\circ}$ 10.172, de 9 de janeiro de 2001, aprovou o Plano Nacional de Educação, o qual apresentou os seguintes objetivos e metas que deveriam ser alcançados na educação infantil, até 2010:

1. Ampliar a oferta de educação infantil de forma a atender, em cinco anos, a 30\% da população de até 3 anos de idade e $60 \%$ da população de 4 a 6 anos (ou 4 e 5 anos) e, até o final da década, alcançar a meta de 50\% das crianças de 0 a 3 anos e $80 \%$ das de 4 a 5 anos;

2. Elaborar, no prazo de um ano, padrões mínimos de infraestrutura para o funcionamento adequado das instituições de educação infantil (creches e pré-escolas) públicas e privadas, que, respeitando as diversidades regionais, assegurem $o$ atendimento das características das distintas faixas etárias e das necessidades do processo educativo quanto a: a) espaço interno, com iluminação, insolação, ventilação, visão para o espaço externo, rede elétrica e segurança, água potável, esgotamento sanitário; b) instalações sanitárias e para a higiene pessoal das crianças; c) instalações para preparo e/ou serviço de alimentação; d) ambiente interno e externo para o desenvolvimento das atividades, conforme as diretrizes curriculares e a metodologia da educação infantil, incluindo o repouso, a expressão livre, o movimento e o brinquedo; e) mobiliário, 
equipamentos e materiais pedagógicos; f) adequação às características das crianças especiais.

A Lei $n^{\circ}$ 13.005, de 25 de junho de 2014, instituiu a atual o Plano Nacional de Educação (PNE) 2014-2024, sendo que esse tem como uma de suas metas a intenção de, até 2016, universalizar e ampliar a oferta de educação infantil em creches de forma a atender, no mínimo, 50\% das crianças de até três anos até o final da vigência deste PNE.

Vemos então que, nos últimos anos, a educação infantil vem conquistando espaço na agenda pública do estado brasileiro, não somente no sentido de ampliar a oferta, mas também no sentido de garantir a qualidade no atendimento. Como exemplo, podemos citar o Programa Nacional de Reestruturação e Aquisição de Equipamentos para a Rede Escolar Pública de Educação Infantil (Proinfância), criado pelo governo federal, por considerar que a construção de creches e pré-escolas, bem como a aquisição de equipamentos para a rede física escolar desse nível educacional, são indispensáveis à melhoria da qualidade da educação. Conforme informações divulgadas no site do Ministério da Educação, entre 2007 e 2014, o Proinfância investiu na construção de 2.543 escolas por meio de convênios; a partir de 2011, com sua inclusão no Plano de Aceleração do Crescimento (PAC2), outras 6.185 unidades de educação infantil foram apoiadas com recursos federais, totalizando 8.728 novas unidades em todo o país. Esse programa federal também repassa recursos materiais para equipar as escolas de educação infantil em fase final de construção, com materiais e mobiliários adequados ao seu funcionamento de modo que mais de 2.500 municípios receberam apoio do FNDE para compra de mesas, cadeiras, berços, geladeiras, fogões e bebedouros. Além disso, o governo federal firmou parceria com universidades públicas no sentido de ofertar assessoria técnico-pedagógica aos municípios que aderiram ao Proinfância, como, por exemplo, ocorreu no Rio Grande do Sul ${ }^{6}$, quando em 2012-2013, em parceria com a UFRGS, 157 municípios gaúchos foram assessorados na qualificação de seus profissionais.

Contudo, precisamos ficar atentos aos impactos que mudanças legais acarretam na educação infantil. Nesse sentido, Flores (2015) alerta sobre alguns riscos que o atual

\footnotetext{
${ }^{6}$ Ver FlORES, Maria Luiza; ALBUQUERQUE, Simone S. (Orgs.). Implementação do Proinfância no Rio Grande do Sul: perspectivas políticas e pedagógicas. Porto Alegre: EDIPUCRS, 2015.
} 
PNE acarreta quando os municípios tentam, com recursos financeiros insuficientes, dar conta das demandas: 1) o fato de as crianças de quatro a cinco anos serem inseridas em espaços escolares organizados para crianças de ensino fundamental, de cunho mais escolarizado, em detrimento das interações e brincadeiras; 2) sofre-se uma redução no direito de escola em tempo integral, pois na intenção de duplicar rapidamente a oferta de vagas, os sistemas municipais optarão por oferecer matrículas em regime parcial; 3) o risco de diminuição na oferta de vagas para crianças de até três anos, no caso de municípios que optem em atender prioritariamente as crianças em idade de matrícula escolar obrigatória; 4) na impossibilidade de atender a demanda, os municípios optem por realizar conveniamento com instituições privadas, sendo que algumas delas podem não atender plenamente os padrões de qualidade.

\section{A Educação Infantil na Base Nacional Comum Curricular (BNCC): quais são as novidades?}

Recentemente, fomos assim interpelados com a colocação de uma professora de educação infantil que atua na rede pública de ensino: "Com essa história da Base, parece que não é mais para elaborar projetos, mas trabalhar por campos de experiência. Lá na escola ninguém mais sabe o que fazer, nem a diretora. Afinal, o que está certo e o que está errado? Daqui a pouco já inventam outras coisas. E agora?".

A criação de uma Base Nacional Comum Curricular (BNCC) está prevista na CF/1988 do Brasil, na LDB/1996 e no PNE/2014, com a intenção de melhorar a qualidade da educação básica e amenizar fortes disparidades entre aquilo que é ensinado nos diferentes locais, estados e regiões brasileiras. Como vimos anteriormente, essas disparidades no atendimento das crianças pequenas foram historicamente produzidas, de modo que as creches ainda hoje lutam para se desvencilhar do clichê de lugares pobres para prestar assistência a crianças pobres. A BNCC define aquilo que todos os alunos têm o direito de aprender, independentemente da região e do local onde estudem. Embora algumas pessoas (pesquisadores, gestores, docentes e discentes) tenham se manifestado contrárias a esse documento, alegando que qualquer tipo de padronização infringe o direito às diferenças e rouba a autonomia das escolas e dos professores, outros entendem como necessário estabelecer conteúdos e competências que os alunos devem 
aprender em cada ano de formação na educação básica, bem como as disciplinas obrigatórias. É importante destacar que cabe a cada sistema, rede de ensino e instituição complementar essa base com uma parte diversificada que atenda as especificidades regionais e locais. Nesse sentido, nos parece bastante claro que a BNCC não pretende universalizar uma proposta curricular fechada, mas garantir aos estudantes os direitos igualitários de aprendizagem em um país com tantas diferenças sociais e econômicas. Ao não definir o currículo em sua integralidade, a BNCC garante a autonomia dos professores, pois estes poderão continuar escolhendo os modos de ensinar e a parte diversificada que precisa ser incluída em cada lugar específico. Além disso, o processo de construção do documento seguiu um caminho bastante democrático no sentido de buscar a participação da comunidade em sua discussão e elaboração.

$\mathrm{Na}$ intenção de fazer uma consulta popular, em 2015, o MEC disponibilizou em seu portal uma versão preliminar do documento elaborado por especialistas. Essa consulta foi amplamente divulgada no sentido de buscar opiniões e sugestões junto à sociedade sobre a versão preliminar. Ouvidas as contribuições da sociedade e da comunidade científica, uma segunda versão do documento foi elaborada e submetida ao Conselho Nacional de Educação.

Considerando as especificidades da educação infantil, a BNCC propõe conviver, brincar, participar, explorar, expressar e conhecer-se como direitos de aprendizagem e desenvolvimento para crianças de zero a cinco anos. Elaborado a partir das DCNEI, esse novo documento adota a concepção de criança proposta na Resolução CNE/CEB 5/2009, ou seja, "sujeito histórico e de direitos, que interage, brinca, imagina, fantasia, deseja, aprende, observa, experimenta, narra, questiona e constrói sentidos sobre a natureza e a sociedade, produzindo cultura". Contudo, a BNCC inova ao subdividir a educação infantil em três grupos por faixa, considerando suas possibilidades de aprendizagem e características do desenvolvimento: bebês (o a 18 meses), crianças bem pequenas (19 meses a 3 anos e 11 meses), crianças pequenas ( 4 anos a 5 anos e 11 meses). Todavia, a BNCC também considera que "esses grupos não podem ser considerados de forma rígida, já que há diferenças de ritmo na aprendizagem e no desenvolvimento das crianças que precisam ser considerados na prática pedagógica (BRASIL, 2017, p. 42). Tanto a BNCC como as DCNEI reconhecem o protagonismo da criança. Se diferenciam do Referencial 
Curricular Nacional para Educação Infantil (RCNEI/1998) por deslocarem o foco centrado nos conteúdos de aprendizagem para as experiências das crianças. De acordo com a BNCC, "campos de experiência se constituem um arranjo curricular que acolhe as situações e as experiências concretas de vida cotidiana das crianças e seus saberes, entrelaçando-os aos conhecimentos que fazem parte do patrimônio cultural” (BRASIL, 2017, p. 38).

Para que os direitos de aprendizagem e desenvolvimento sejam garantidos, 0 currículo da educação infantil está organizado nos seguintes campos de experiência: 1) 0 eu, o outro e o nós; 2) Corpo, gestos e movimentos; 3) Traços, sons, cores e formas; 4) Escuta, fala, pensamento e imaginação; 5) Espaços, tempos, quantidades, relações e transformações. O documento também explicita brevemente cada um desses campos e especifica os objetivos de aprendizagem e desenvolvimento para cada faixa etária.

A divulgação da terceira versão da Base Nacional Comum Curricular, em abril de 2017, foi alvo de muita polêmica’, pois um dos Campos de Experiência, elencados nas duas primeiras versões da BNCC, teve sua nomenclatura modificada, de "Escuta, fala, linguagem e pensamento" para "Oralidade e Escrita", o que gerou críticas entre muitos setores da Educação Infantil. Entre elas, as vindas por parte das coordenadoras do Projeto Leitura e Escrita na Educação Infantil: Maria Fernanda Nunes - UNIRIO; Mônica Correia Baptista - UFMG; Patrícia Corsino - UFRJ; Vanessa Ferraz Almeida Neves - UFMG; Angela Maria Rabelo Barreto - FMEI, Rita de Cássia de Freitas Coelho - MIEIB. Segundo esse grupo, houve um enxugamento no texto e isso comprometeu tanto a distinção entre as concepções de linguagem e de ensino/aprendizagem, quanto à compreensão da linguagem escrita na educação infantil. Problematizam o quanto esse foco na leitura e escrita se contrapõe ao que está previsto nas DCNEI/2009, reduzindo esse campo de experiência à apropriação das linguagens oral e escrita.

O que está em jogo não seria a antecipação da escolarização com predomínio da leitura e escrita e da matemática em detrimento das múltiplas linguagens? Além disso, a avaliação em larga escala não seria uma armadilha com a incorporação da Educação Infantil no PNAIC - Programa Nacional de Alfabetização na Idade Certa? Uma educação a

Ver: http://juntospelaeducacao.com.br/educacao-infantil-na-nova-versao-da-base-nacional-comumcurricular/. 
partir dessa lógica não seria uma estratégia de contenção da pobreza, organizada a partir de políticas redistributivas compensatórias? Tal lógica não estaria se afastando da ideia de políticas redistributivas estruturais? A educação das crianças pequenas vem sendo estratégia para a contenção da pobreza. "Parceiros" do governo federal, propõem, implantam e executam programas educacionais: Instituto Lemamm, Instituto Ayrton Senna, Itaú bancos, entre outros.

Discutir direitos de aprendizagem e desenvolvimento é importante, mas não é no papel que eles ficam garantidos. Não basta que se redija e se aprove um documento 'avulso', sem políticas públicas e previsão orçamentária - e isso nossa história já mostrou em diversos momentos: 'ou se forma professores ou se constrói escolas', 'ou se compra merenda escolar ou se compra brinquedos'. A implementação da BNCC requer que se considere uma multiplicidade de fatores que merecem destaque na agenda do Estado: exige investimentos na formação de professores, na construção de novas escolas, na qualidade dos espaços e dos materiais. Fazer políticas públicas não é “ou isto ou aquilo" a exemplo de uma operação "tapa-buracos".

Afinal, como garantir direitos de aprendizagem e desenvolvimento para crianças pequenas de quatro a cinco anos que estão sendo alocadas em Escolas de Ensino Fundamental, em regime de tempo parcial e um currículo que prioriza a aquisição de conhecimentos no campo da leitura, da escrita e da matemática? Como garantir esses mesmos direitos aos bebês e crianças bem pequenas quando suas escolas estão sendo entregues pelos Sistemas Municipais de Educação para administração por parte da Assistência Social? Como colocar em funcionamento um currículo organizado por campos de experiência em escolas sucateadas e sem um programa profícuo de formação de professores em serviço?

Parece-nos que nesse século XXI entramos de marcha à ré na história da educação das crianças de zero a cinco anos. Ou seja, a falta de financiamento público e o aumento das instituições filantrópicas, nos leva de volta a uma educação assistencialista para atendimento de crianças de zero a três anos. E, quando se trata de crianças de quatro a cinco anos, há um retorno à educação compensatória, centrada na antecipação da escolarização. 
De acordo com o artigo 15 da Resolução CNE/CP n² 2, de 22 de dezembro de 2017, que institui e orienta a implantação da Base Nacional Comum Curricular, as instituições ou redes de ensino já podem alinhar seus currículos e propostas pedagógicas à BNCC, sendo que essa adequação deve ser efetivada preferencialmente até 2019 e no máximo, até início do ano letivo de 2020.

A indagação sobre a BNCC feita pela professora citada no início deste texto, nos inquieta e, de certa forma, nos angustia. Assim como ela, muitos outros profissionais da educação infantil estão confusos sobre 'como' concretizar no dia a dia das escolas públicas os direitos de aprendizagem e desenvolvimento das crianças do século XXI.

\section{Considerações finais}

A relação creche-pobreza naturalizou-se ao longo de nossa história. Foi a custo de muitas manifestações populares que a educação das crianças de zero a cinco anos entrou na agenda do poder público. Contudo, ainda hoje as creches e pré-escolas ocupam os últimos lugares na fila de espera para serem percebidas e ouvidas em suas demandas pelos setores públicos. Com o reconhecimento da educação infantil como um direito da criança e como parte integrante da educação básica, buscou-se ampliar o atendimento e, ao mesmo tempo, amenizar as desigualdades na oferta de atendimento pelos sistemas de ensino nas diferentes regiões brasileiras.

Desde então, constatam-se iniciativas do Ministério da Educação no sentido de instrumentalizar as escolas, organizando, apoiando e distribuindo materiais orientadores, os quais também estão disponibilizados no portal do $M E C^{8}$. Mudanças de concepções sobre infância, criança, currículo e educação infantil presentes nesses documentos têm surtido discussões científicas e renovações legais, mas os efeitos dessas mudanças ainda são reféns de minguados investimentos na qualidade da educação infantil e da educação em geral.

Embora se reconheçam os avanços no que tange aos compromissos que vêm sendo gradativamente assumidos pelo estado brasileiro a partir da CF/1988, precisamos

8 Disponível em: http://portal.mec.gov.br/secretaria-de-educacao-basica/publicacoes?id=12579:educacaoinfantil. Acesso em: 20 maio 2017. 
ser humildes em reconhecer que temos muitas deficiências nesse atendimento, em especial no que se refere àquele direcionado aos bebês e crianças bem pequenas.

Certamente a BNCC pode contribuir para garantir os direitos de aprendizagem a todas as crianças, mas isso, por si, só é insuficiente para que mudanças significativas se concretizem. Para além de uma base comum, a garantia do direito de aprender e de se desenvolver requer políticas educacionais que priorizem e concretizem investimentos em espaços, aquisição de materiais e formação de professores para a educação infantil. Afinal, mais do que novos discursos, a educação das crianças brasileiras precisa mesmo é de ações políticas que interrompam a tradição herdada da sociedade colonial e escravista quando o atendimento esteve associado à pobreza, à doença, ao abandono e violência doméstica. Avançar na educação não se restringe a produzir novos documentos; exige, isso sim, que concretizemos políticas que viabilizem a garantia daquilo que já lhes é garantido por lei, desde a Constituição Federal (1988) e do Estatuto da Criança e do Adolescente (1990).

\section{Referências}

ARCE, Alessandra. Compre o Kit neoliberal para a educação infantil e ganhe grátis os dez passos para se tornar um professor reflexivo. Educação e Sociedade, São Paulo, ano XXII, n. 74, p. 251-283, abril. 2001.

BRASIL. Decreto n. 7.247 de 19 de abril de 1879 do Ministério do Império. Reforma o ensino primário e secundário no município da Corte e o superior em todo o Império. Império do Brasil de 1879 - Parte II Tomo XLII. Rio de Janeiro: Tipografia Nacional, p. 196217,1879 .

BRASIL. Decreto-Lei n².024, de 17 de fevereiro de 1940. Fixa as bases da organização da proteção à maternidade, à infância e à adolescência em todo o País. Diário Oficial da União, Brasília, DF, Seção 1, p. 3125, 23/2/1940.

BRASIL. Decreto-Lei ${ }^{\circ} 229$, de 28 de fevereiro de 1967. Altera dispositivos da Consolidação das Leis do Trabalho, aprovada pelo Decreto-Lei $n^{\circ} 5.452$, de $1^{\circ}$ de maio de 1943, e dá outras providências. Diário Oficial da União, Brasília, DF, Seção 1, p. 2423, 28/2/1967.

BRASIL. Decreto-Lei $n^{\circ}$ 5.452, de $1^{\circ}$ de maio de 1943. Aprova a Consolidação das Leis do Trabalho. Diário Oficial da União, Brasília, DF, Seção 1, p. 11937, 9/8/1943. 
BRASIL. Lei $\mathrm{n}^{\circ}$ 5.692/71 de 11 de agosto de 1971. Fixa diretrizes e bases para o ensino de $1^{\circ} \mathrm{e}$ $2^{\circ}$ graus, e dá outras providências. Brasília, DF, [1971]

BRASIL. [Constituição (1988)]. Constituição da República Federativa do Brasil. Brasília: Senado Federal, 1988. Disponível em:

<https://www2.senado.leg.br/bdsf/bitstream/handle/id/518231/CF88_Livro_EC91_2016.pdf >. Acesso em: 10 ago. 2017.

BRASIL. [Estatuto da criança e do adolescente (1990)]. Estatuto da criança e do adolescente: lei n. 8.069, de 13 de julho de 1990, e legislação correlata [recurso eletrônico]. - $9^{\text {a }}$ ed. Brasília: Câmara dos Deputados, Edições Câmara, 2012. Disponível em: <http://www.crianca.mppr.mp.br/arquivos/File/publi/camara/estatuto_crianca_adolescent e_ged.pdf $>$. Acesso em: 12 mar. 2017.

BRASIL. Lei n 9.394, de 20 de dezembro de 1996. Lei de Diretrizes e Bases da Educação Nacional. Brasília: Senado Federal, 2005. Disponível em:

<https://www2.senado.leg.br/bdsf/bitstream/handle/id/70320/65.pdf>. Acesso em: 10 abr. 2017.

BRASIL. Secretaria de Educação Fundamental. Coordenação Geral de Educação Infantil. Referencial curricular nacional para a educação infantil. Brasília, DF: MEC/SEF/COEDI, 1998.

BRASIL. Lei $\mathbf{n}^{\circ}$ 10.172, de 9 de janeiro de 2001. Aprova o Plano Nacional de Educação e dá outras providências. Disponível em:

http://portal.mec.gov.br/setec/arquivos/pdf_legislacao/tecnico/legisla_tecnico_lei10172.p df>. Acesso em: 20 jun. 2018.

BRASIL. Lei $\mathbf{n}^{\circ}$ 11.274, de 6 de fevereiro de 2006. Disponível em:

<http://www2.camara.leg.br/legin/fed/lei/2006/lei-11274-6-fevereiro-2006-540875-

publicacaooriginal-42348-pl.html>. Acesso em: 14 jul. 2018.

BRASIL. Emenda Constitucional ${ }^{\circ}$ 59, de 11 de novembro de 2009. Disponível em: <http://www.andi.org.br/sites/default/files/legislacao/legislacao_emenda_constitucional_ 59_2009.pdf>. Acesso em: 20 mar. 2018.

BRASIL. Ministério da Educação; Conselho Nacional de Educação; Câmara de Educação Básica. Resolução CNE/CEB n ${ }^{5}$, de 17 de dezembro de 2009. Fixa as Diretrizes Curriculares nacionais para a educação infantil. Disponível em:

<http://www.seduc.ro.gov.br/portal/legislacao/RESCNE005_2009.pdf>. Acesso em: 10 maio 2018.

BRASIL. Ministério de Educação. Conselho Nacional de Educação. Câmara de Educação Básica. Resolução CNE/MEC, Nº 1, de abril de 1999. Diretriz Curricular Nacional de Educação Infantil. Diário Oficial da União, Brasília, DF, 13 de abril de 1999. Seção 1, p.18. 
BRASIL. Conselho Nacional de Educação. Câmara de Educação Básica. PARECER n: 20/2009. Revisão das diretrizes curriculares nacionais para a educação infantil, Brasília, DF, 2009.

BRASIL. Lei n 12.796, de 4 de abril de 2013. Altera a Lei no 9.394, de 20 de dezembro de 1996, que estabelece as diretrizes e bases da educação nacional, para dispor sobre a formação dos profissionais da educação e dar outras providências. Disponível em: <http://www.forpedi.com.br/downloads/forpedi_anexo_2204131434180.pdf>. Acesso em: 15 ago. 2018.

BRASIL. Lei 13.005/14. Aprova o Plano Nacional de Educação e dá outras providências. Congresso Nacional. Disponível em: < http://www2.camara.leg.br/legin/fed/lei/2014/lei13005-25-junho-2014-778970-publicacaooriginal-144468-pl.html>. Acesso em: 09 nov. 2018.

BRASIL. Ministério da Educação. Secretaria de Educação Básica. Base Nacional Comum Curricular- $3^{\text {a }}$ versão revista. Brasília, DF: MEC/SEB, 2017. Disponível em: http://basenacionalcomum.mec.gov.br/images/BNCC_20dez_site.pdf. Acesso em 20 out. 2018.

BUJES, Maria Isabel E. Escola Infantil: Pra que te quero? In: CRAIDY, Carmem e KAERCHER, Gládis (Orgs.). Educação infantil: pra que te quero? Porto Alegre: Artmed, 2001. p. 13-22.

CAMPOS, Maria Malta. A educação Infantil como direito. In: Insumos para debates 2 ementa Constitucional $n^{\circ}$ 59/2009 e a educação infantil: impactos e perspectivas. São Paulo: Campanha Nacional pelo Direito à Educação, 2010. p. 10-14.

CAMPOS, Maria Malta. A legislação, as políticas nacionais de educação infantil e a realidade: desencontros e desafios. In.: MACHADO, Maria Lucia de A. (Org.). Encontros e desencontros em educação infantil. São Paulo: Cortez, 2002. p. 27-33.

DROUET, Ruth Caribé da Rocha. Fundamentos da educação pré-escolar. São Paulo: Ática, 1990.

FARIA, Ana Lúcia G. de; PALHARES, M. S. (Orgs.). Educação infantil pós LDB: rumos e desafios. 2.ed. São Paulo: Autores Associados, 2000.

FERRARI, Alceu R. Pré-escola para salvar a escola? Educação e Sociedade, São Paulo, n. 12, p. 29-37, setembro, 1982.

FLORES, Maria Luiza; ALBUQUERQUE, Simone S. (Orgs.). Implementação do proinfância no Rio Grande do Sul: perspectivas políticas e pedagógicas. Porto Alegre: EDIPUCRS, 2015.

GUIMARÃES, Célia Maria. A história da atenção à criança e da infância no Brasil e o surgimento da creche e da pré-escola. Revista Linhas. Florianópolis, v. 18, p. 80-142, set./dez. 2017. 
KUHLMANN, Moysés Jr. Infância e educação infantil: uma abordagem histórica. Porto Alegre: Mediação, 1998.

KRAMER, Sonia (Coord.) et al. Com a pré-escola nas mãos: uma alternativa curricular para a educação infantil. 6. ed. São Paulo: Ática, 1993.

MORROW, Raumond Allen; TORRES, Carlos Alberto. Teoria social e educação: uma crítica das teorias da reprodução social e cultural. Porto Alegre: Afrontamento, 1997.

MARCILIO, Maria Luiza. A roda dos expostos e a criança abandonada do Brasil - 17261950. In: FREITAS, Marco César de. História social da infância no Brasil. São Paulo: Cortez, 1999.

OLIVEIRA, Zilma Ramos de. Educação infantil: fundamentos e métodos. São Paulo: Cortez, 2002a.

OLIVEIRA, Zilma Ramos de. Creches no sistema de ensino. In: MACHADO, Maria Lucia de A. (Org.). Encontros e desencontros em educação infantil. São Paulo: Cortez, 2002b. p. 79-82.

PAIVA, Vanilda Pereira. Educação popular e educação de adultos: contribuições à história da educação brasileira. São Paulo: Loyola, 1973.

ROSENBERG, Fúlvia. Organizações multilaterais, Estado e políticas de educação infantil. Cadernos de Pesquisa, São Paulo: Fundação Carlos Chagas, n. 115, p. 25-64, março, 2002.

SANCHEZ, Ana. Os parâmetros curriculares nacionais e as críticas apresentadas. Pátio, Porto Alegre, n. 10, p. 13-18. fev./abr. 1997.

SILVA, Tomaz Tadeu da. Documentos de identidade: uma introdução às teorias do currículo. 2. ed. Belo Horizonte: Autêntica, 2002. 